\title{
An Empirical Insight: Accountable Care Organizations' Profitability and Quality Drivers
}

\author{
Andrey Mikhailitchenko*, Hugh Pforsich
}

Andrey Mikhailitchenko*, Hugh Pforsich

College of Business Administration, California State University Sacramento,

Sacramento, California, USA.

\section{Correspondence}

Dr. Andrey Mikhailitchenko,

College of Business Administration, California State University Sacramento, 6000 , J. St., Sacramento, 95819, USA. Mobile no: +1-916-2787128

Email:mikhaili@csus.edu

History

- Submission Date: 30-03-2020

- Revised Date: 08-06-2020

- Accepted Date: 25-08-2020

DOI : 10.5530/ijmedph.2020.4.34

Article Available online

http://www.ijmedph.org/v10/i4

\section{Copyright}

(C) 2020 Phcog.Net. This is an openaccess article distributed under the terms of the Creative Commons Attribution 4.0 International license.

\begin{abstract}
Since their inception in 2012, accountable care organizations (ACOs) have yielded inconsistent and unpredictable financial results. These outcomes may be related to an individual ACO's participant mix of primary care physicians (PCPs) and specialists. We analyzed ACO performance data to better understand the cooperative roles of PCPs and specialists in financially successful ACOs. The dataset included several variables reflecting different quantitative and qualitative characteristics of ACO performance. The analyses of variance and covariance (ANOVA and ANCOVA) were used as the primary statistical tool. The obtained results provided the evidence that a larger number of PCPs in an ACO can help to achieve quantitative goals related to immediate financial effect. In contrast, ACOs with a higher relative share of specialists tend to improve the healthcare quality and profitability in the longer term. The results provide a solid basis for further investigation that may help future ACOs to design the strategies resulting in efficient quality care and sustainable profitability.

Key words: Healthcare, Triple Aim, Medicare, Statistical Testing, Analysis of Variance.
\end{abstract}

\section{INTRODUCTION}

Accountable care organizations (ACOs) in the Medicare Shared Savings Program (MSSP) are groups of doctors (PCPs and specialists), hospitals and other healthcare providers who participate voluntarily to give coordinated high-quality care to a population of at least 5,000 Medicare fee-for-service beneficiaries (patients). The "Triple Aim" of ACOs is 1) to enhance patient care experiences and 2) to improve the health of populations while, at the same time, 3) reducing the growth of expenditures.

The ACO payment model seeks to promote both high quality of care and efficient utilization of resources. Specific cost and quality benchmarks are used to measure the performance of providers over a period of time. If providers as a group perform successfully in relation to this benchmark, they share in the cost savings and receive payment from Medicare after each performance year for their share of the cost savings.

Since the Medicare Shared Savings Program (MSSP) began in 2012, only about half of the initial ACOs were able to achieve shared savings in their first three-year contract period. It has been difficult to determine the key factors that cause some ACOs to succeed financially while others fail to achieve shared savings. An individual ACO's participant mix of primary care and specialist physicians may be a significant factor. Given the conflicting constraints imposed by the ACO expenditure benchmark that determines generated savings and the quality score that discounts shared savings, we analyzed the performance data of ACOs at the beginning of the MSSP to better understand the cooperative roles of PCPs and specialists in financially successful ACOs.

\section{Conceptual Framework}

This article analyzes ACO performance data to identify the constructive roles and limitations of primary care physicians (PCPs) and specialists in the financial success of ACOs. This research evaluates ACO performance data from the human resources perspective to identify those factors that influence the marketing and financial success of ACOs.

\section{Payment Model}

The ACO payment model seeks to tie provider reimbursements to quality metrics and reductions in the total cost of care for an assigned population of patients. ${ }^{1}$ It is intended to realign financial incentives so that high value, coordinated and preventive care is promoted and unnecessary, duplicative and poorly coordinated care is avoided. ${ }^{2}$

The primary care physician is well-suited to the ACO payment model with a focus on preventive care and the coordination of downstream services from specialists and other provider types. The specialist, on the other hand, is somewhat conflicted when seeking payment from the ACO payment model incentivizing decreased utilization along with quality improvement. Given these conflicting constraints, we analyzed recent performance data to better 
understand the cooperative roles of PCPs and specialists in financially successful ACOs.

\section{ACO Expenditure Benchmarks}

The Centers for Medicare and Medicaid Services (CMS) determine the expenditure benchmark of each individual ACO for a given performance year by calculating a historical benchmark based on the three prior years for those beneficiaries who would have qualified to be in that particular ACO during those years. ${ }^{3}$ Each of the calculations for these three years is weighted differently with the first (oldest) year at $10 \%$, the second year at $30 \%$ and the third (most recent) year at $60 \%$.

\section{ACO Quality Scores}

For the data set analyzed in this study, CMS used 33 measures to determine an ACO's annual quality score. These measures are in four key domains, including patient/caregiver experiences ( 7 measures), care coordination/patient safety ( 6 measures), preventive health ( 8 measures) and at-risk populations (12 measures). The overall quality score is a percentage used to limit the shared savings dollars that each ACO is rewarded. ${ }^{4}$

\section{Literature Review}

Healthcare marketing is an important component of a broader services marketing domain. A recent development in healthcare such as the establishment of ACOs has created the need for research aimed at the development of innovative marketing techniques to secure ACOs' financial feasibility.

\section{Historical Perspective of ACO Research}

ACOs became the subject of academic and practical research immediately after their inception. The major research questions put forward were mostly related to the theoretical and empirical substantiation of the idea that healthcare quality improvement and cost reduction could occur simultaneously. These topics were also focal for the scholarly research that took place in the earlier period before ACOs were established. Fisher et al. ${ }^{5}$ determined that Medicare beneficiaries are receiving their healthcare from relatively coherent systems of local physicians and hospitals, supporting the arguments promoting the promise of ACOs as effective extensions of the hospital medical staff. Crosson ${ }^{6}$ advocated the idea that the payment reforms in healthcare systems are critical and that the Medicare program can be instrumental in starting the necessary transformations in payment design, incentives and delivery system structure. Wennberg et al. ${ }^{7}$ based on the example of Americans with severe chronic illnesses, discussed the key points of a strategy aimed at providing them with the access to ACOs with highquality evidence-based prospective care.

\section{Literature on ACO Environments}

A substantial body of research performed after the inception of ACOs is focused on examining the characteristics of the communities and customer segments being served by ACOs. The major goal pursued by these studies is to make a delineation between different customer groups and determine which ones provide a better fit to the combination of the goals of healthcare quality improvement, on one hand and related costs reduction on the other. According to Lewis et al. ${ }^{8}$ many areas of the country may not be suitable for successful implementation of ACOs. Cantor et al. ${ }^{9}$ found a substantial variation in the share of highuser hospital patients across the study communities and high rates of avoidable utilization and costs among these patients. Eggbeer et al. ${ }^{10}$ discuss key factors that should be considered in the ACO segmentation strategy, including the use of segment-specific language, exclusive co- branding and automatic price increases if volume for that segment is not achieved.

\section{Literature on ACO Characteristics}

Another stream of research is developed in the direction of identifying optimal characteristics of ACO that would secure their efficient performance. These characteristics include multiple dimensions such as organizational, financial, quality measurement and patient identification variables. High fill and Ozcan ${ }^{11}$ identified composite measures of productivity and quality constructs and found that attributing successes in efficiency or quality improvement solely to the practices and characteristics of the ACO model may be misleading. Stuart et al. ${ }^{12}$ using the difference-in-difference (DD) method, found no evidence that the ACO model called the 'Alternative Quality Contract' (AQC) affected out-of-pocket health service expenditures of enrollees. Feldman ${ }^{13}$ describes the theory and practice of shared savings payment systems and summarizes recent contracting initiatives in the private sector.

\section{RESEARCH QUESTION AND HYPOTHESES}

The key practical business question for this study is: What combination of an ACO's PCPs and specialists can best achieve the "Triple Aim" objective while at the same time maximizing the ACO's shared savings gross profit margin? Based on that business question, several research questions were formulated as a set of hypothesized effects reflecting the relationships between the human resources and financial performance factors in ACOs performance.

For each of the 333 ACOs, the data set included the number of Primary Care Physicians (PCP), Specialist, Nurse Practitioners, Physician Assistants, Clinical Nurse Specialists who assigned billing rights to an ACO participant in the performance period. Only the PCP and Specialist data were used in this study.

The major practical considerations while formulating hypothesized effects were related to the difference between the role of primary care physicians and specialists in ACOs. A primary care physician is well suited to the ACO payment model with a focus on preventive care and the coordination of downstream services from specialists, hospitals, skilled nursing facilities and home health. The specialist, on the other hand, is somewhat conflicted when seeking payment from different payment models: encouraging increased utilization and the ACO model incentivizing decreased utilization along with quality improvement. Based on these considerations, we hypothesize the opposite direction of the influence of the number of PCPs, on one hand and the number of specialist, on the other hand, as indicators characterizing an ACOs' potential to generate savings:

H1: The number of PCPs in an ACO is positively related to its savings rate

H2: $\quad$ The number of specialists in an ACO is negatively related to its savings rate

H3: The number of PCPs in an ACO positively influences its savings generation ability

H4: $\quad$ The number of specialists in an ACO negatively influences its savings generation ability

H5: $\quad$ The number of PCPs in an ACO positively influences its total shared savings

H6: $\quad$ The number of specialists in an ACO negatively influences its total shared savings

The rationale for the next set of hypotheses is based on the general assumption that both PCPs and specialists are important for maintaining high quality of service in healthcare organizations. The research literature suggests that the most common problems lowering the quality 
of healthcare services in ACOs seem to be related to lack of resources and expertise and low confidence in treating more complex conditions, ${ }^{14}$ i.e. to factors other than the ratio between PCPs and specialists. Based on this premise, we hypothesize that both PCPs and specialists constitute an important resource positively influencing those ACO metrics that are related to the quality, as follows:

H7: $\quad$ The number of PCPs in an ACO positively influences its quality score

H8: $\quad$ The number of specialists in an ACO positively influences its quality score

H9: The number of PCPs in an ACO positively influences its final shared savings rate

H10: The number of specialists in an ACO positively influences its final shared savings rate

The third set of hypotheses is based on the notion that except for the number of PCPs and specialists and the ratio between them, there may be some other important resource-related factors that can influence financial and quality indicators of ACOs' performance, such as their size and age. The literature demonstrates that many factors traditionally influencing the quality of ACO service (technology, information systems, equipment etc.) are dependent upon the size and duration of operation of organizations ${ }^{15,16}$ and can affect ACO performance in parallel with human resource related factors (number of PCPs, specialists etc.).

Based on the above, the third set of hypotheses operationalizing age and size control variables is the following:

H11: The number of PCPs in ACO positively influences its quality score, controlling for the ACO age

H12: The number of PCPs in ACO positively influences its final shared savings rate, controlling for the ACO age

H13: The number of specialists in ACO positively influences its final shared savings rate, controlling for the ACO age

H14: The number of specialists in ACO negatively influences its savings generation ability, controlling for the ACO size

H15: The number of specialists in ACO negatively influences its total shared savings, controlling for the ACO size

Graphically the set of hypothesized effects can be represented as follows (Figure 1):

\section{MATERIALS AND METHODS}

The data set analyzed in this study is the MSSP ACO Public Use File. ${ }^{17}$ Select data categories in the data set include total number of assigned beneficiaries, total benchmark expenditures, total expenditures, total

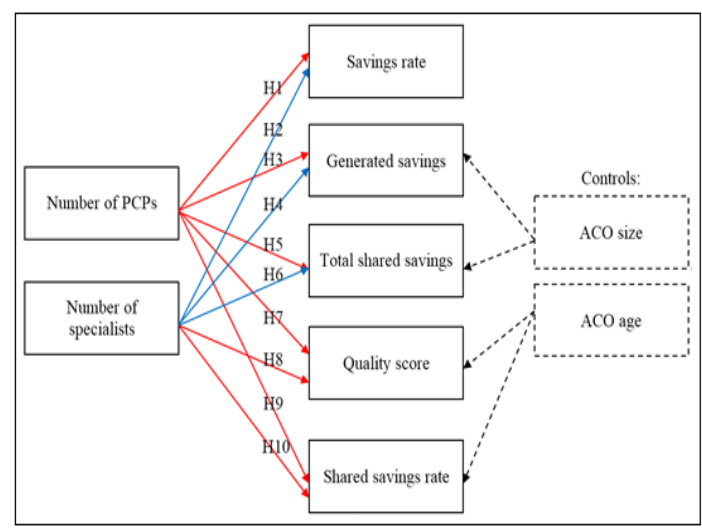

Figure 1: Hypothesized Effects. ${ }^{1}$ benchmark minus total assigned beneficiary expenditures, generated savings, earned shared savings payments and quality performance scores. A series of two-way analysis of variance (ANOVA) tests was used to detect the relationships between variables included in the data set. Two grouping variables selected were the number of PCPs and the number of specialists in the 333 ACOs who reassigned billing rights to an ACO participant in the performance period.

Five measures of ACO performance were used as dependent variables for each of the ANOVAs: 1) total generated savings, 2) total shared savings, 3) savings rate, 4) quality score and 5) final sharing rate.

1) Total generated savings are the total savings for ACOs whose savings equaled or exceeded their minimum savings rates.

2) Total shared savings are the ACO's share of earned savings that equaled or exceeded their minimum savings rates and who were eligible for a performance payment because they met the program's quality performance standard.

3) Savings rate is the total benchmark expenditure minus assigned beneficiary expenditures as a percent of the total benchmark expenditure.

4) Quality score is a composite percentage score based on each ACO's performance in providing quality healthcare using 33 measures in 4 key domains (Patient/Caregiver Experience, Care Coordination/Patient Safety, Preventive Health and At-Risk Population).

5) Final sharing rate is the quality performance sharing rate multiplied by the ACO's quality score. This is the percentage of savings an ACO shares if the ACO is eligible for shared savings.

For testing Hypotheses 11 through 15 where variables such as size and age of ACOs were used as covariates, the analysis of covariance (ANCOVA) was applied.

\section{RESULTS}

Overall, the statistical analysis generated somewhat mixed results. They are represented in the Tables 1-3.

\section{Expected Results}

The results show that the number of specialists who reassigned billing rights to ACO participants in the performance period is negatively related to the ACO's total amount of generated and, respectively, shared savings. However, detection of this statistically significant relationship requires the use of ACO size as the control variable due to the fact that in larger ACOs the absolute amount of generated savings tends to be higher. While ACO participants collectively are aimed at value-based healthcare services, specialists individually are more interested in extensive processes, repeat visits and technologically-sophisticated and costly procedures.

On the other hand, the results indicate that the number of specialists is positively related to the overall ACO quality score. Since the ACO final sharing rate is a function of the quality score, it is also positively

Table 1: Influence of number of PCPs on ACO performance: ANOVA tests.

\begin{tabular}{ccccc} 
& $\begin{array}{c}\text { Total group } \\
(n=333)\end{array}$ & $\begin{array}{c}\text { PCP1 } \\
(n=166)\end{array}$ & $\begin{array}{c}\text { PCP2 } \\
(n=167)\end{array}$ & $p$ value \\
\hline Savings Rate (H1) & .573800 & .771767 & .377019 & .608 \\
Generated Savings (H3) & $2,421,043$ & $1,805,672$ & $3,047,603$ & $.007^{1^{* * *}}$ \\
Total Shared Savings (H5) & $1,024,763$ & 721,411 & $1,326,299$ & $.005^{2^{* * *}}$ \\
Quality Score (H7) & .826 & .828 & .825 & .935 \\
Shared Savings Rate (H9) & .442 & .437 & .447 & .520
\end{tabular}


Table 2: Influence of number of specialists on ACO performance: ANOVA tests.

\begin{tabular}{ccccc} 
& $\begin{array}{c}\text { Total group } \\
(\boldsymbol{n}=333)\end{array}$ & $\begin{array}{c}\text { Sp1 } \\
(n=166)\end{array}$ & $\begin{array}{c}\text { Sp2 } \\
(\boldsymbol{n}=167)\end{array}$ & $p$ value \\
\hline Savings Rate (H2) & .573800 & 1.18219 & -.03094 & $.025^{3^{* *}}$ \\
Generated Savings (H4) & $2,421,043$ & $2,322,078$ & $2,519,416$ & $.066^{4^{*}}$ \\
Total Shared Savings (H6) & $1,024,763$ & 933,348 & $1,115,631$ & $.096^{*}$ \\
Quality Score (H8) & .826 & .781 & .871 & $.017^{7^{* *}}$ \\
Shared Savings Rate (H10) & .442 & .430 & .454 & .125
\end{tabular}

Table 3: Adjustment for control variables effect: ANCOVA tests.

\begin{tabular}{|c|c|c|c|c|}
\hline Covariate & Hypothesis & Effects & F value & $p$ value \\
\hline \multirow[t]{6}{*}{ ACO age } & \multirow{2}{*}{$\begin{array}{l}\text { H11 (Number of PCPs } \\
\rightarrow \text { Quality Score) }\end{array}$} & Main & .033 & .857 \\
\hline & & Covariate & 2.437 & .120 \\
\hline & \multirow{2}{*}{$\begin{array}{l}\text { H12 (Number of PCPs } \\
\rightarrow \text { Shared Savings Rate) }\end{array}$} & Main & .414 & .521 \\
\hline & & Covariate & 42.608 & $.000^{*+*+}$ \\
\hline & \multirow{2}{*}{$\begin{array}{c}\text { H13 (Number of } \\
\text { specialists } \rightarrow \text { Shared } \\
\text { Savings Rate) }\end{array}$} & Main & 3.975 & $.047^{* *}$ \\
\hline & & Covariate & 42.608 & $.000^{* *+}$ \\
\hline \multirow[t]{4}{*}{ ACO Size } & \multirow{2}{*}{$\begin{array}{c}\text { H14 (Number of } \\
\text { specialists } \rightarrow \text { Generated } \\
\text { Savings) }\end{array}$} & Main & 5.160 & $.024^{* *}$ \\
\hline & & Covariate & 8.199 & $.004^{* * *}$ \\
\hline & \multirow{2}{*}{$\begin{array}{c}\text { H15 (Number of } \\
\text { specialists } \rightarrow \text { Total Shared } \\
\text { Savings) }\end{array}$} & Main & 4.489 & $.035^{* *}$ \\
\hline & & Covariate & 9.008 & $.003^{n+*}$ \\
\hline
\end{tabular}

In summary, the results of this group of hypothesis tests are as follows:

$* * *$ Significant at .01 level of confidence

** Significant at .05 level of confidence

* Significant at .10 level of confidence

influenced by the number of specialists in an ACO (controlled for ACO age). This finding suggests that in the long term, specialists perform the role of a quality driver and potentially can become a brand image generator.

The analysis reveals a strong positive relationship between the number of PCPs and the amount of both total generated savings and total shared savings. PCPs perform the role of a "streamliner" of the ACO healthcare logistics that optimizes the value supply chain and generates savings.

\section{Unexpected Results}

The number of PCPs was found to be not significantly positively related either to the ACO's savings rate or quality score (and respectively to the final shared savings rate). Another unexpected result is that the number of specialists in an ACO does not significantly negatively influence the ACO's savings generation ability and its final shared savings rate. These results show that though the contrast between the impact of of PCPs and specialists on different aspects of an ACO's financial performance really exists, it is not overwhelmingly applicable to every single component of this performance, at least based on the data set used in this study.

\section{DISCUSSION}

The set of the research questions put forward in the study can be summarized as the direction of influence of the number of PCPs and specialists on ACO financial and quality performance indicators.

\section{Findings}

The major finding is that PCPs in an ACO can help to achieve quantitative goals related to immediate financial effect while ACO specialists tend to improve an ACO's healthcare quality and profitability in the longer term. It is incumbent on the PCP, as an ACO participant under the ACO payment model, to refer beneficiaries to those specialists that are not only reputed for high quality care, but also have a mind to eliminate unnecessary utilization costs in alignment with the ACO payment model. When this balance between quality and frugality is struck by nearly all participants in an ACO, shared savings and profits are more likely to be achieved.

It can be stated that this research provides a first step toward the development of an optimum ACO participant mix of PCPs and specialist physicians that will increase an ACO's likelihood of achieving shared savings.

\section{Limitations and Implications for Future Research}

There are several limitations of our study that should be addressed. First, the results of this study only indicate positive and negative influences of the number of PCPs and specialists on ACO measures of success. The results did not indicate what ACO beneficiary population size, ACO age and ACO ratio of PCPs to specialists are optimal for generating shared savings and profit. Second, the data used in this study are not longitudinal and included data points from many regions of the country with differing patient demographics and levels of health acuity risk. Therefore, the results of analyzing this data may not be totally generalizable to ACOs in specific regions of the country.

Based on the results of this research, several potential extensions come to mind. It would be useful to investigate the specific qualities of ACO participants that may be driving ACO financial success. Specialist physicians are of particular interest as research subjects for ACO performance because of their contribution to the overall quality score of an ACO. The quality scores and claim costs of both ACO-participant specialists and non-ACO-participant specialists who receive referrals from ACO participants and whose billing rights are assigned to the ACO need to be further analyzed. Except that, the effect of different risksharing models (Tracks 1,2 and 3) on ACO success should be compared.

\section{CONCLUSION}

In order to achieve sustainable financial success, ACOs must provide primary and specialty care that is both cost effective and high quality. Given the high percentage of ACOs that have dropped out since it began in 2012, the optimum participant mix of primary care and specialty physicians has not been easy to identify. This study sought to empirically measure the coordinated impact of the number of PCPs and specialists on an ACO's cost savings and healthcare quality measures. These results provide a solid basis for further investigation that may help future ACOs to design their participant rosters with a mix of PCPs and specialists that will lead to efficient quality care and sustainable profitability.

\section{ACKNOWLEDGEMENT}

We thank participants of the American Marketing Association Conference for their helpful feedback. The financial support of the California State University Sacramento College of Business Administration is gratefully acknowledged.

\section{CONFLICT OF INTEREST}

The authors declare that there is no conflict of interest

\section{ABBREVIATIONS}

ACO: Accountable Care Organizations; PCP: Primary Care Physicians; HMO: Health Management Organizations; CMS: Centers for Medicare 
and Medicaid Services; ANOVA: Analysis of Variance; ANCOVA: Analysis of Covariance.

\section{REFERENCES}

1. Schommer JC, Carlson AM, Rhee TG. Validating pharmaceutical product claims: questions a formulary committee should ask. J of Med Econ. 2015;18(12):10006. https://doi.org/10.3111/13696998.2015.1108917

2. Keren R, Littlejohns P. Consideration of social values in the establishment of accountable care organizations in the USA. J of Health Organ and Manag. 2012;26(3):384-9. https://doi.org/10.1108/14777261211239025

3. U.S. Department of Health and Human Services. Shared savings and losses and assignment methodology. Medicare Shared Savings Program Specifications. 2017;5:1-66.

4. Centers for Medicare and Medicaid Services. Accountable care organization 2016 program quality measure narrative specifications. RTI Int Rep. 2016;1-31.

5. Fisher ES, Staiger DO, Bynum JPW, et al. Creating accountable care organizations: the extended hospital medical staff. Health Aff. 2007;26(1):44-57. https://doi.org/10.1377/hlthaff.26.1.w44

6. Crosson FJ. Medicare: the place to start delivery system reform. Health Aff. 2009;28(2):232-4. https://doi.org/10.1377/hlthaff.28.2.w232

7. Wennberg JE, Fisher ES, Skinner JS, et al. Extending the P4P agenda, part 2: how Medicare can reduce waste and improve the care of the chronically ill. Health Aff. 2007;26(6):1575-85. https://doi.org/10.1377/hlthaff.26.6.1575

8. Lewis VA, Colla $\mathrm{CH}$, Carluzzo KL, et al. Accountable care organizations in the United States: Market and demographic factors associated with formation. Health Serv Res. 2013;48(6):1840-58. https://doi.org/10.1111/1475-6773.12102

9. Cantor JC, Chakravarty S, Tong J, et al. The New Jersey Medicaid ACO
Demonstration Project: Seeking opportunities for better care and lower costs among complex low-income patients. J of Health Politics: Policy and Law. 2014;39(6):1185-211. https://doi.org/10.1215/03616878-2822622

10. Eggbeer B, Sears K, Homer K. Partnering with payers? Key lessons to keep in mind. Healthc Financ Manag. 2014;68(1):84-9. Gale Academic OneFile (accessed March 23, 2020)

11. Highfill T, Ozcan Y. Productivity and quality of hospitals that joined the Medicare Shared Savings Accountable Care Organization Program. Int J of Healthc Manag. 2016;9(3):210-7. https://doi.org/10.1179/2047971915Y.0000000020

12. Stuart EA, Huskamp HA, Duckworth $K$, et al. Using propensity scores in difference-in-differences models to estimate the effects of a policy change. Health Serv and Outcomes Res Methodol. 2014;14(4):166-82. https://doi. org/10.1007/s10742-014-0123-z

13. Feldman R. The economics of provider payment reform: Are accountable care organizations the answer?. J of Health Politics: Policy and Law. 2015;40(4):74560. https://doi.org/10.1215/03616878-3150038

14. Bagayogo I, Turcios-Wiswe P, Taku K. et al. Providing Mental Health Services in the Primary Care Setting: The Experiences and Perceptions of General Practitioners at a New York City Clinic. Psychiatr Q. 2018;89(4):897-908. https:// doi.org/10.1007/s11126-018-9587-2

15. Edwards S, Marino T, Balasubramanian M, et al. Burnout Among Physicians, Advanced Practice Clinicians and Staff in Smaller Primary Care Practices. J of Gen Intern Med. 2018;33(12):2138-46. https://doi.org/10.1007/s11606-0184679-0

16. Heisey-Grove D, King JA. Physician and practice-level drivers and disparities around meaningful use progress. Health Serv Res. 2017;52(1):244-67. https:// doi.org/10.1111/1475-6773.12481

17. Centers for Medicare and Medicaid Services. 2014 Shared Savings Program (SSP) accountable care organizations (ACO). Public Use File. 2017;1-24.

Cite this article : Mikhailitchenko A, Pforsich H. An Empirical Insight: Accountable Care Organizations' Profitability and Quality Drivers. Int J Med Public Health. 2020;10(4):155-9. 